
\title{
$\begin{array}{ll}\text { Research Square } & \begin{array}{l}\text { Preprints are preliminary reports that have not undergone peer review. } \\ \text { They should not be considered conclusive, used to inform clinical practice, } \\ \text { or referenced by the media as validated information. }\end{array}\end{array}$
}

\section{The association of maternal postpartum depression with infant weight growth: a prospective birth cohort study}

\section{Qiong He}

Central South University Xiangya School of Public Health

\section{Gang Cheng}

Central South University Xiangya School of Public Health

\section{Simin $\mathrm{He}$}

Central South University Xiangya School of Public Health

\section{Gang Tian}

Central South University Xiangya School of Public Health

Xiaowei Xie

Central South University Xiangya School of Public Health

\section{Ni Jiang}

Central South University Xiangya School of Public Health

\section{Xianying Min}

Central South University Xiangya School of Public Health

\section{Chao Li}

Central South University Xiangya School of Public Health

Rui Li

Central South University Xiangya School of Public Health

\section{Yan Shi}

Central South University Xiangya School of Public Health

\section{Tong Zhou}

Central South University Xiangya School of Public Health

Yan Yan ( $\sim$ yanyan@csu.edu.cn )

Central South University Xiangya School of Public Health

\section{Research Article}

Keywords: maternal postpartum depression, weight growth, linear mixed model, generalized estimating equation

Posted Date: September 20th, 2021

DOI: https://doi.org/10.21203/rs.3.rs-852252/v1 
License: (ㅇ) (1) This work is licensed under a Creative Commons Attribution 4.0 International License. Read Full License 


\section{Abstract \\ Background}

Untreated maternal postpartum depression has consequences for infant weight, which may vary with infant growth time and postpartum depression duration. Dynamic assessment of the association between maternal postpartum depression and infant weight growth is crucial for early detection of the suspicious abnormal effects of maternal postpartum depression on infant weight growth and taking corresponding intervention measures. But, none of published studies continuously and dynamically evaluated these effect changes on infant weight growth. This study was aimed to evaluate the dynamic effects of maternal postpartum depression on infant weight growth at a prospective birth cohort.

\section{Methods}

960 mother-infant pairs between 2015 to 2018 in Changsha, China were followed up at ages of 1, 3, 6, 8, and 12 months. Data were obtained through household surveys. Depression of mothers was assessed at 1 month postpartum. Linear mixed models and generalized estimating equation models were used to test the connection and its changes between maternal postpartum depression and infant weight growth at five different periods of 1-12 months.

\section{Results}

$8.0 \%$ of mothers reported postpartum depression. Adjusted linear mixed models showed a negative association between maternal depression at 1-month postpartum and infant weight at 1 month, 1-3 months, 1-6 months, 1-8 months, and 1-12 months, in which infants with depressed mothers were the lighter weight of $0.14 \mathrm{~kg}$ (95\% Cl:0.02, 0.25), $0.13 \mathrm{~kg}(95 \% \mathrm{Cl}: 0.02,0.24), 0.13 \mathrm{~kg}(95 \% \mathrm{Cl}: 0.02,0.24), 0.13 \mathrm{~kg}(95 \% \mathrm{Cl}: 0.02,0.24)$, and $0.16 \mathrm{~kg}$ $(95 \% \mathrm{Cl}: 0.04,0.27)$ relative to not depressed respectively. Generalized estimating equation models showed a positive association between maternal depression at 1-month postpartum and infant underweight at 1 month and 1-3 months, in which infants of maternal depression had higher risk ratio of underweight in 3.19 $(95 \% \mathrm{Cl}: 1.38,7.34)$ and $3.19(95 \% \mathrm{Cl} .1 .32,7.70)$ compared to those mothers were not depressed accordingly.

\section{Conclusions}

Maternal postpartum depression was continuously associated with a lighter weight of ifants from 1 to 12 months and higher risk of being underweight in infants from 1 to 3 months. It seems important to put early prevention, screening, diagnosis, and treatment of maternal depression into practice as soon as possible to avoid adverse consequences.

\section{Background}

Maternal postpartum depression (PPD) is considered a major depressive disorder (MDD) with a global prevalence of $0.5 \%-68.8 \%$ depending on used diagnostic standards $[1,2]$. Generally, PPD begins within 4 to 6 
weeks after delivery, and clinical symptoms similar to MDD may enlist depressed mood, loss of interest or pleasure in activities, sleep disturbance, appetite disturbance, loss of energy, feelings of worthlessness or guilt, diminished concentration, irritability, anxiety, and thoughts of suicide [3, 4]. Evidence suggested that mothers in postpartum have a greater risk of depression than other periods even up to 20 times, and untreated PPD has consequences for infant weight which were not limited to the time of depression screened [1, 5-13].

At present, explanatory mechanisms of how maternal PPD affected infant weight growth were based on the following hypotheses [6-17]: (1) Maternal PPD may affect maternal rearing behavior and quality, especially feeding behavior, as well as the quantity and quality of interaction between mother and infant, thus resulted in a change in infant weight growth. (2) The effects of maternal PPD on infant weight growth may vary with infant growth time and duration of maternal PPD, and these effects were not limited to infancy, but also extended to early childhood, preschool, school-age, adolescence, and even adulthood.

To date, many epidemiologic studies examined the association between maternal PPD and infant weight growth which may vary with the income level of population [1, 15, 18-27]. Maternal PPD seemed to stunt infant weight growth in India [19-20], Bangladesh [21], Zambia [22], Nigeria [23], Latin America [24] and other low-income countries. However, in United States [25], Europe [26], and other high-income countries, maternal PPD seemed to have no or few associations with infant weight gain. But none of previous research reported dynamic associations between maternal PPD and infant weight, because most of their data used a single time-point infant-weight measurement from cross-sectional or cohort survey [15, 18-23, 25-28], which ignoring effect changes of maternal PPD on infant weight after1-month postpartum and longer. Dynamic evaluation of the association between maternal PPD and infant weight can not only reveal the duration of the impact of maternal PPD on infant weight growth, but also clearly reflect the change characteristics of the impact of maternal PPD on infant weight growth at different stages, so as to find out the suspected abnormal growth impact of maternal PPD on infant weight as soon as possible and take intervention measures. Moreover, the majority of published studies did not fully control the confounding factors at the individual and family level of infants and mainly used $t$-test, chi-square test, analysis of variance, correlation analysis and other basic statistical methods in the statistical analysis, which may be unable to clearly estimate the effect size of maternal PPD on infant weight growth $[15,19-23,25-28]$.

The weight growth of infants is crucial to early childhood even the entire life. Simultaneously, the effects of maternal PPD on infant weight growth were not limited to its screened time. Therefore, it is urgent to do some prospective panel data studies in China, which has 500,000 to 8.6 million new mothers with postpartum depression every year [29-30], to characterize effect changes of maternal PPD on infant weight growth [31-36], and then reveal the character and duration of maternal PPD on infant weight to take timely intervention measures to improve the growth level in infancy even childhood. Thus, this study was designed, to evaluate the dynamic effects of maternal PPD on the growth of infant weight by linear mixed models (LMM) and generalized estimating equation (GEE) models in a prospective birth cohort.

\section{Methods}

\section{Study Design and Subjects}


This study was designed as a prospective ongoing birth cohort study, which was initiated in 2015 and conducted in three communities in the Kaifu District of Changsha City, Hunan Province, China. Subjects were recruited from the mothers and their infants after birth in Changsha City of Hunan province from January to December 2015, and then received face-to-face questionnaires at 1, 3, 6, 8, and 12 months. The inclusion criteria included: (1) mothers and infants were inhabitants in the Kaifu District of Changsha City; (2) mothers and infants had complete health care records in the Community Health Management Information System (CHMIS); (3) mothers agreed to participate in the investigation and signed written informed consents. Exclusion criteria included: (1) mothers had severe mental illnesses or brain diseases; (2) mothers were unable to give informed consent.

\section{Measures}

\section{Depressive symptoms}

Depressive symptoms of mothers were assessed at 1 month postpartum with a self-report ten-item depression subscale of Edinburgh Postpartum Depression Scale (EPDS) [37]. The EPDS scale has 10 items, including mood, fun, self-blame, anxiety, fear, insomnia, coping ability, sadness, crying and self-injury, and each item has 0 to 3 points with a total of 30 points. We calculated depression subscale scores and used a cut-off value of 8 points to screen postpartum depression which was recommended by Lee et al [38].

\section{Infant weight and covariates}

Outcomes of interest were infant weights at 1, 3, 6, 8, and 12 months, obtained by self-designed questionnaires through household surveys. And the weight was then converted into weight-for-age z score (WAZ) by the child growth standards of Department of maternal and child health and community health, Ministry of health of China in 2009 [39], which WAZ less than - 2 was defined as underweight of infants.

Variables possibly linked with maternal PPD or infant weight were chosen as covariates [40-43], including:

(1) Maternal covariates: maternal age $(<25,25-29,30-34,30$, or $\geq 35$ years old), education (junior school or below, senior high school, or bachelor degree or above), pre-pregnancy BMI $\left(<24,24-27.9,28 \mathrm{~kg} / \mathrm{m}^{2}\right)$, history of gestation (primiparous or multiparous), pregnancy disease (yes or no), daily use of mobile phones during pregnancy (frequent use or infrequent use), and average monthly household income $(\leq 2000,2001-5000$, or $>$ $5000 \mathrm{RMB})$, feeding pattern of infants from birth to 12 months with five-time periods including birth to 1 month, 1 to 3 months, 3 to 6 months, 6 to 8 months and 8 to 12 months (breastfeeding, mixed feeding, artificial feeding). Pre-pregnancy BMI (Body Mass Index) $\left(\mathrm{BMI}=\right.$ weight $(\mathrm{kg}) /$ height $\left.(\mathrm{m})^{2}\right)$ greater than 24 and smaller than 28 was indicated overweight, greater than 28 was indicated obesity.

(2) Infant covariates: infant gender (male or female), gestational week ( $<37$, or $\geq 37$ weeks), birth weight ( $<2500$, $2500-3999$, or $\geq 4000 \mathrm{~g}$ ). Gestational age less than 37 full weeks was defined as a premature infant. Birth weight less than $2500 \mathrm{~g}$ was defined as low birth weight and greater than $3999 \mathrm{~g}$ was defined as macrosomia according to Obstetrics and gynecology (9th ed) [44].

\section{Sample size}


Given the probable persistence of the effect of maternal PPD on infant weight growth and the regular pattern of infant weight growth over time, we hypothesized that the association between maternal PPD and infant weight was negative and varied with weight growth, and tested this hypothesis by carrying out a prospective birth cohort study. Thus, the sample size of this study was estimated based on the calculation formula of a cohort study [45]. Previous literature reported that the rate of underweight in infants with non-depressed mothers at 1year-old was 3.3\% [24]. We assumed that the relative risk $(R R)$ of the maternal PPD group was 4.0 and did with a two-sided test by $a=0.05$ and $\beta=0.10$, then the total sample size required was 713 .

\section{Statistical analysis}

Frequency, rate, mean and standard deviation were used to describe group information of subjects. A Chi-square test was used to compare the differences in maternal-infant characteristics between maternal PPD and non-PPD infants. Repeated measures ANOVA was used to test the growth pattern of infant weight in different months between depressed and non-depressed mothers and identify the interaction of maternal PPD and potential confounding factors with time on infant weight.

Linear mixed model (LMM) was used to examine the association between maternal PPD and infant weight at five periods of 1-12 months, including 1 month, 1 to 3 months, 1 to 6 months, 1 to 8 months, 1 to 12 months, which maternal PPD as the independent variable, infant weight as the dependent variable, potential confounding variables maternal age, education, pre-pregnancy BMI, history of gestation, pregnancy disease, daily use of mobile phones during pregnancy, average monthly household income, and feeding pattern of infants from birth to 12 months, infant gender gestational week, birth weight as covariates. And the interaction between maternal-infant variables and time found in repeated measures ANOVA would be introduced in the model as well. Unstructured (UN) structure of $G$ (variance/covariance of random effect) matrix was selected in LMM model which considered in most cases ${ }^{46}$ and unrestricted structure of $R$ (residual variance/covariance) matrix was assumed.

In addition, when the LMM model fitting results showed an association between maternal PPD and infant weight, the generalized estimation equation (GEE) model was used to test the connection between maternal PPD and infant underweight at different periods of 1-12 months, which maternal PPD as the independent variable, infant underweight as the dependent variable, maternal confounding variables found to be related to infant weight by LMM fitting as the covariates. We used binomial distribution and log link function in our GEE model analyses.

2InL, AIC, BIC of information criteria were used to evaluate the LMM models fitting effect, and QIC of information criteria was used to evaluate the GEEs models fitting effect. Estimates of regression coefficients $(\beta)$ and corresponding 95\% confidence intervals (Cl), risk ratio $(R R)$ and corresponding 95\% confidence intervals (Cl) were used to quantify the effects of maternal PPD in LMM and GEE models respectively. A two-tailed $P$-value less than 0.05 was considered to be statistically significant. All statistical analyses were completed in statistical software IBM SPSS 22.

\section{Results}

The flow chart of participants in this birth cohort study was shown in Fig. 1. After excluding the mothers who were none inhabitant and had no health care records $(n=265)$, refused to investigate $(n=45)$, did not complete 
the PPD scale $(n=16), 960$ mother-infant pairs were included in our study. Besides, there were $8(0.8 \%), 23$ (2.5\%), 30 (3.2\%), 43 (4.7\%) infants who were lost to follow-up at 3 months, 6 months, 8 months, and 12months, respectively.

Background data of the involved 960 maternal-infant pairs between maternal PPD and the non-PPD group were listed in Table 1. In total, 77 mothers reported PPD 1 month after delivery, and the prevalence of maternal PPD was $8.0 \%$. Mothers who had pregnancy disease, more daily use to mobile phones during pregnancy, lower average monthly household income, premature and low birth weight infants were more likely to reported PPD, while mothers who were obese before pregnancy reported lower rates. Further, depressed mothers were more towards mix and artificial feeding in the first month of their infants (see Table 1).

Table 1 Sample maternal and infant characteristics categorized by maternal postpartum depression 


\section{Characteristics}

Maternal characteristics

Age (years)

$<25$

25-29

30-34

$\geq 35$

Education

Junior school or below

Senior high school

Bachelor degree or above

Pre-pregnancy BMI $\left(\mathrm{kg} / \mathrm{m}^{2}\right)^{\mathrm{A}}$

$<24$

24-27.9

$\geq 28$

History of gestation

Primiparous

Multiparous

Pregnancy disease

Yes
No
$\begin{aligned} & \text { Daily use of mobile phones during } \\ & \text { pregnancy }\end{aligned}$
pregnancy

\section{Frequent use}

Infrequent use

Average monthly household income $(\mathrm{RMB})^{\mathrm{B}}$

$$
\leq 2000
$$

2001-5000

$>5000$

Feeding pattern of infants from birth to
Total $(n=960)$

$\operatorname{PPD}(n=77)$

Non-
$\operatorname{PPD}(n=883)$
0.132

$41(85.4)$

407(91.3)

317(92.4)

115(95.8)

$0.35 \quad 0.840$

\begin{tabular}{lll}
33 & $3(9.1)$ & $30(90.9)$ \\
\hline 117 & $11(9.4)$ & $106(90.6)$ \\
797 & $63(7.9)$ & $734(92.1)$
\end{tabular}

$6.350 .042^{*}$

168(90.8)

418(90.3)

280(95.2)

$2.06 \quad 0.103$

452(93.4)

430(90.5)

$11.73 \quad 0.001^{*}$

$\begin{array}{lll}119 & 19(16.0) & 100(84.0) \\ 831 & 57(6.9) & 774(93.1)\end{array}$

$21.14<0.001^{\star}$

$\begin{array}{lll}321 & 44(13.7) & 277(86.3) \\ 639 & 33(5.2) & 606(94.8)\end{array}$

$6.250 .044^{\star}$

25(83.3)

448(90.5)

383(93.9) 
1 months $^{B}$

\begin{tabular}{llll} 
Breastfeeding & 784 & $48(6.1)$ & $736(93.9)$ \\
\hline Mixed feeding & 157 & $24(15.3)$ & $133(84.7)$ \\
\hline Artificial feeding & 19 & $25(26.3)$ & $14(73.7)$
\end{tabular}

Feeding pattern of infants from 1 to 3 months

\begin{tabular}{llll} 
Breastfeeding & 642 & $45(7.0)$ & $597(93.0)$ \\
\hline Mixed feeding & 93 & $13(14.0)$ & $80(16.0)$ \\
\hline Artificial feeding & 212 & $17(8.0)$ & $195(92.0)$
\end{tabular}

Feeding pattern of infants from 3 to 6 months

\begin{tabular}{llll} 
Breastfeeding & 203 & $17(8.4)$ & $186(91.6)$ \\
\hline Mixed feeding & 220 & $23(10.5)$ & $197(89.5)$ \\
\hline Artificial feeding & 510 & $33(6.5)$ & $477(93.5)$
\end{tabular}

Feeding pattern of infants from 6 to 8 months

\begin{tabular}{|c|c|c|c|c|c|}
\hline Breastfeeding & 87 & $5(5.7)$ & $82(94.3)$ & & \\
\hline Mixed feeding & 342 & $29(8.5)$ & $313(91.5)$ & & \\
\hline Artificial feeding & 491 & $39(7.9)$ & $452(92.1)$ & & \\
\hline $\begin{array}{l}\text { Feeding pattern of infants from } 8 \text { to } 12 \\
\text { months }\end{array}$ & & & & 1.53 & 0.465 \\
\hline Breastfeeding & 38 & $5(13.2)$ & 33(86.8) & & \\
\hline Mixed feeding & 619 & $48(7.8)$ & $571(92.2)$ & & \\
\hline Artificial feeding & 242 & $18(7.4)$ & $224(92.6)$ & & \\
\hline \multicolumn{6}{|l|}{ Infant characteristics } \\
\hline Gender & & & & 0.34 & 0.559 \\
\hline Male & 493 & $42(8.5)$ & $451(91.5)$ & & \\
\hline Female & 467 & $35(7.5)$ & $432(92.5)$ & & \\
\hline Gestational week(weeks) & & & & 5.50 & $0.019^{*}$ \\
\hline$<37$ & 46 & $8(17.4)$ & $38(82.6)$ & & \\
\hline$\geq 37$ & 898 & $69(7.7)$ & 829(92.3) & & \\
\hline Birth weight (g) & & & & 7.54 & $0.023^{*}$ \\
\hline$<2500$ & 28 & $6(21.4)$ & $22(78.6)$ & & \\
\hline
\end{tabular}




$\begin{array}{ccll}2500-3999 & 865 & 68(7.9) & 797(92.1) \\ \geq 4000 & 60 & 3(5.0) & 57(95.0)\end{array}$

Note:PPD: postpartum depression, Non-PPD: none of the postpartum depression. Values are $n(\%)$. Level of

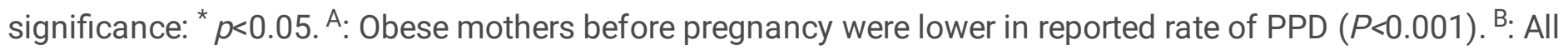
pairwise comparison within the group were significant $(P<0.01)$. Due to the missing value of some variables, the total number of cases in subgroups was slightly different from the total number of cases.

The measurement results of weight in infants at different months were listed in Table 2. The result of repeated measures ANOVA showed infant weight was linearly gained by month with the largest type III square and mean square $(F=22232.89 \llbracket P<0.05)$ and there was a difference between depressed and non-depressed mothers over the 12-months $(F=6.76 \otimes P<0.01)$. Thus, we considered using the linear model as the basic mixed model to fit the growth trajectory of infant weight, and added the interaction covariates of infant gender $(F=14.62, P<0.001)$ and birth weight $(F=14.62, P<0.001)$ with month-old to model to examine the effect of maternal PPD on weight growth of infant during different periods. Ultimately, estimated fixed-effect parameters of maternal PPD in the final LMM models at five different periods of 1-12 months were shown in Table 3. Furthermore, effects parameter estimations of maternal PPD on underweight of infants in final GEEs models were shown in Table 4.

LMM analyses indicated that maternal PPD was negatively associated with infant weight from 1 to 12 months $(P<0.05)$ (see Table 3). GEEs analyses found that maternal PPD was positively related to infant underweight from 1 to 3 months $(P<0.05)$ (see Table 4). On closer analysis, the average weights of infants with maternal PPD were $0.14 \mathrm{~kg}, 0.13 \mathrm{~kg}, 0.13 \mathrm{~kg}, 0.13 \mathrm{~kg}$, and $0.16 \mathrm{~kg}$ lighter than that without PPD at 1 month, $1-3$ months, $1-6$ months, 1-8 months, and 1-12 months respectively (see Table 3 ). Then, the risks of being underweight in maternal PPD infants were 3.19 times and 3.19 times higher than that none of PPD at 1 month and 1-3 months accordingly (see Table 4).

Table 2 Weight measurements of infants among depressed and non-depressed mothers at different months

\begin{tabular}{|lllll|}
\hline Month & \multicolumn{2}{l}{ PPD } & \multicolumn{2}{c|}{ Non-PPD } \\
\cline { 2 - 5 } & $\boldsymbol{M}$ & $\boldsymbol{S D}$ & $\boldsymbol{M}$ & $\boldsymbol{S D}$ \\
\hline 1 month & 4.22 & 0.67 & 4.53 & 0.55 \\
\hline 3 months & 6.41 & 0.82 & 6.66 & 0.76 \\
\hline 6 months & 7.99 & 0.8 & 8.17 & 0.9 \\
\hline 8 months & 8.72 & 0.88 & 8.91 & 0.98 \\
\hline 12 months & 9.55 & 0.86 & 9.79 & 1.05 \\
\hline
\end{tabular}

Note: PPD: postpartum depression, Non-PPD: none of the postpartum depression, M: mean, SD: standard deviation. 
Table 3 Fixed effects estimation of maternal PPD in LMM models at different periods

\begin{tabular}{|lcccl|}
\hline Models (normal as control) & $\boldsymbol{\beta}(95 \% \mathrm{Cl})$ & $\boldsymbol{S}_{\boldsymbol{\beta}}$ & $\boldsymbol{t}$ & $\boldsymbol{P}$ \\
\hline Mode 1 (1 months ) & $-0.14(-0.25,-0.02)$ & 0.06 & -2.38 & $0.017^{*}$ \\
\hline Mode 2 (1 to 3 months) & $-0.13(-0.24,-0.02)$ & 0.06 & -2.31 & $0.020^{*}$ \\
\hline Mode 3 (1 to 6 months) & $-0.13(-0.24,-0.02)$ & 0.05 & -2.29 & $0.022^{*}$ \\
\hline Mode 4 (1 to 8 months) & $-0.13(-0.24,-0.02)$ & 0.06 & -2.24 & $0.025^{*}$ \\
\hline Mode 5 (1 to 12 months) & $-0.16(-0.27,-0.04)$ & 0.06 & -2.79 & $0.005^{*}$ \\
\hline
\end{tabular}

Note: Level of significance:* $p<0.05$. Model1: $2 \ln L=1085.10, A I C=1129.10$, and $B I C=1233.91$. Model 2: 2InL=2633.53, AIC=2691.53, and $B I C=2849.26$. Model 3: $2 \mathrm{InL}=4121.22$, $\mathrm{AIC}=4197.23$, and $\mathrm{BIC}=4418.53$. Model 3: $2 \mathrm{InL}=5313.73, \mathrm{AIC}=5409.74$, and $\mathrm{BIC}=5702.21$. Model $4: 2 \mathrm{InL}=6682.27, \mathrm{AIC}=6680.27$, and $\mathrm{BIC}=7170.70$.

Table 4 Effects estimation of maternal PPD on underweight infants in GEE models during different periods of 112 months

\begin{tabular}{lllllll} 
Models(normal as control) & \multicolumn{2}{c}{ Underweight (\%) } & $R R(95 \% \mathrm{Cl})$ & Wald $\chi^{2}$ & $\boldsymbol{P}$ \\
\cline { 2 - 6 } & PPD & Non-PPD & & & \\
\hline Mode 1(1 month ) & $9.46 \%$ & $2.83 \%$ & $3.19(1.38,7.34)$ & 7.42 & $0.006^{*}$ \\
\hline Mode 2(1 to 3 months) & $6.80 \%$ & $2.08 \%$ & $3.19(1.32,7.70)$ & 6.67 & $0.010^{*}$ \\
\hline Mode 3 (1 to 6 months) & $5.00 \%$ & $1.78 \%$ & $2.52(0.98,6.45)$ & 1.86 & 0.055 \\
\hline Mode 4 (1 to 8 months) & $3.72 \%$ & $1.67 \%$ & $1.99(0.75,5.27)$ & 1.90 & 0.168 \\
\hline Mode 5 (1 to 12 months) & $3.01 \%$ & $1.74 \%$ & $1.37(0.54,3.50)$ & 0.45 & 0.505 \\
\hline
\end{tabular}

Note: PPD: postpartum depression, Non-PPD: none of the postpartum depression. Level of significance:* $p<0.05$. Model1 adjusted the variable of maternal pre-pregnancy BMI (QIC=271.19). Model 2 adjusted the variable of maternal pre-pregnancy BMI ( $Q I C=422.76)$, Model 3 adjusted the variable of maternal pre-pregnancy BMI $(Q I C=551.28)$. Model 4 adjusted the variable of maternal pre-pregnancy BMI (QIC=654.48). Model 5 adjusted the variable of maternal pre-pregnancy $\mathrm{BMI}$ and parity $(\mathrm{QIC}=826.31)$.

\section{Discussion}

This birth cohort study reveals two majors findings. First, infants of postpartum depressed mothers were continuously lighter than infants of non-depressed mothers from 1 to 12 months,even after adjustment for confounding factors, and these weight differences in infants were declined at the 3rd month and peaked at the 12th month. Second, maternal depression at 1 month postpartum was associated with underweight infants 
from 1 to 3 months, but not significant at 6-12 months. Thus, both the results were found to support the study hypotheses.

The negative association between maternal postpartum depression and infant weight growth found in this study was consistent with those of developing countries [19-24], but this study added some new findings that this negative association changed dynamically and lasted throughout infancy. Various factors contribute to these new findings, but likely at least two factors.

First, postpartum depression could impair mothers to feed their infant healthily and properly, infants with high dependence and nutritional needs on the depression mothers were more likely to have lightweight or low weight. For one thing, exclusive breastfeeding for infants in the first 6 months recommended by the World Health Organization was critical for infants to obtain adequate nutrition [47]. However, the majority of published studies reported depressed mothers were more commonly to cease exclusive breastfeeding in the first and second months [1, 48-49]. In this study, we also found that depressed mothers were more likely to discontinue exclusive breastfeeding in the first month after comparing the differences of feeding patterns in infants between depressed and non-depressed mothers in five time periods, which there was no difference in the other four periods. In addition, it has been proven that early discontinue of exclusive breastfeeding was a key factor in infant under-nutrition. Thus, early cessation of exclusive breastfeeding by depressed mothers may lead to their infants being lighter and more prone to low weight in the first 3 months when infants were highly dependent on breastfeeding. For another, depression mothers were more intrusive in mother-infant interaction of feeding practice such as more stress, restrictive and emotional feeding to infants, and more breastfeeding problems (e.g. increased breastfeeding difficulties, lack of breastfeeding confidence, and decreased levels of breastfeeding self-efficacy) due to their depression symptoms [48,50-56], and this could make it difficult or impossible for infants to establish a sense of security for mothers, which made infants more likely to unhealthy eating behavior, and then delay weight gain according to the attachment theory [54, 57]. A cohort study in Austria reported that maternal depression was associated with less responsive feeding practices at 2 years postpartum [52]. Although we did not find any difference in feeding patterns of infants between depressed and non-depressed mothers in the other four-time periods except the first month, the difference in feeding quality in these time periods may also lead to the slowdown of infant weight growth. In future research, we will further clarify the association between feeding quality and infant weight growth.

Second, the duration of maternal depression and the catch-up growth of low birth weight infants and may play a mediating role in explaining the continuous and dynamic association between maternal postpartum depression and infant weight growth. Firstly, although it is unclear whether maternal postpartum depression can account for infant weight growth beyond the current period of depression [58], several studies have reported a long-term association extending to preschool stage [24,59], which reflected postpartum depression may become chronicity. Besides, there was some evidence that mothers were chronic exposure to depression from 2 weeks to 6 months postpartum with various incidence [14,60-61], but we did not examine the association of the duration of maternal PPD and infant weight growth because of the evaluation of maternal PPD by single time in our population. Secondly, studies have confirmed that mothers of low birth weight infants were more likely to report postpartum depression [42] which also found in this study, and low birth weight infants were usually catch-up growth in infancy when given by appropriate nutrition after birth but still lighter than normal birth weight infants [62-64]. Thus, to some extent, the catch-up growth of low birth weight infants may explain that maternal 
postpartum depression was not associated with low-weight infants after 3 months when there was no difference in feeding patterns of infants between depressed and non-depressed mothers.

Our findings have important implications. First, our results add new growing evidence that the effect of maternal depression at 1-month postpartum on the negative growth of infant weight is continuous, changing, and regular in the whole of infancy. Larger-scale and longer-term studies are recommended to evaluate the long-term impacts of maternal depression from pre-pregnancy to postpartum even longer on infant and children's psychological and physical development based on these combination models. Second, our results underscore the urgency of screening and treatment of postpartum depression and even perinatal depression in China. Although in 2015, the American College of Obstetricians and gynecologists recommended that clinicians should screen perinatal women for depressive symptoms at least once [65],but over half of the mothers who suffered postpartum depression remained undiagnosed and untreated [66]. Similarly, China's pre-pregnancy and pregnancy health care guidelines (2018) clearly put forward the need for timely mental health education and guidance for pregnant women to prevent depression [67]. However, at this stage, there is still a lack of routine screening and diagnosis of maternal mental health problems in China's maternal health management services [68]. A recent study in Canada reported that PPD screening brought about an incremental cost-effectiveness ratio (ICER) of $\$ 17,644$ per quality adjusted life year (QALY), which resulted in an annual 813 (11\%) additional diagnosed cases and 120 additional gained QALYs compared to not screening at a population level, and if $100 \%$ attending referral, the ICER fell to $\$ 13,908$ per QALY, which resulted in an annual 1997 (27\%) additional diagnosed cases and 249 additional gained QALYs [65].Thus, depression screening should be added to the maternal health management of basic public health service projects in China in the future, and pregnant women with positive screening should focus on strengthening psychological guidance and refer them to psychiatric hospitals for intervention treatment when necessary.

\section{Limitations}

This study was primarily limited by two aspects as follows. First, we collected our data from three streets of Kaifu District, Changsha City, China, limiting generalizability to some extent. However, our data of infant development, growth, and health were from a whole population birth cohort of the targeted community, which will be traced to the pre-school age from the maternal pregnancy, and collected as comprehensively as possible through household surveys, health information system and extraction of children's health manual. Therefore, to some extent, the infants' demographic, growth, and development characteristics of this birth cohort and large sample population are basically consistent. Second, the collection of maternal PPD data requires mothers to recall experiences from delivery to 1 month postpartum, which may have a recall bias. However, strict investigation training, proper investigation skills, standard content filling, and timely quality control of on-thespot investigation are also adopted to reduce this bias in this study.

\section{Conclusions}

This study found that the association between maternal postpartum depression and infant weight was negative, dynamic, and continuous in the whole infant period, but the association with the low weight of infants was only significant in the first 3 months. Future research is recommended to focus on the longer-term effects of postpartum depression on children's physical and psychological development. And future policymaking is

Page 13/19 
recommended to pay attention to prevent, screen, and treat depression of pregnant women to avoid poor growth of children.

\section{Abbreviations}

BMI: body mass index, CHMIS: community health management information system, EPDS: Edinburgh postpartum depression scale, GEE: generalized estimating equation, LMM: linear mixed models, MDD: major depressive disorder, PPD: postpartum depression, WAZ: weight-for-age z score.

\section{Declarations}

\section{Acknowledgments}

This work was supported by Health and Family Planning Commission, Sifangping Street Community Health Center, Dongfeng Road Street Community Health Center and Xinhe Street Community Health Center of Changsha in Hunan province.

\section{Funding}

This research was funded by the National Natural Science Foundation of China, grant number 81973153, $81673276,81373101$.

\section{Availability of data and materials}

The datasets analyzed specifically for use in this study are not publicly available due to on-going research, but reasonable requests for data can be made to corresponding author at the end of the research.

\section{Author' contributions}

YY and QH designed the study; QH performed data pre-processing and data analysis, and drafted the manuscript; GC, SMH, GT, XWX, NJ, XYM, CL, RL, YS, and TZ interpreted the findings and critically reviewed and edited the manuscript. $Y Y$ finalized the manuscript. All authors reviewed and approved the final manuscript.

\section{Ethics approval and consent to participate}

All methods performed in studies involving human participants were in accordance with the ethical standards of the institutional and/or national research committee (The Independent Ethics Committee of Clinical Pharmacology Institute, Central South University, Changsha, China (CTXY-130041-3-2) and with the 1964 Helsinki declaration and its later amendments or comparable ethical standards. Written informed consent was obtained from all individual participants include in the study.

\section{Consent for publication}

Not applicable.

\section{Competing interests}


The authors declare that they have no competing interests.

\section{References}

1. Slomian J, Honvo G, Emonts $P$, et al. Consequences of maternal postpartum depression: A systematic review of maternal and infant outcomes. Womens Health (Lond). 2019; 15: 1-55.

2. Halbreich U, Karkun S. Cross-cultural and social diversity of prevalence of postpartum depression and depressive symptoms. J Affect Disord. 2006; 91 (2-3): 97-111

3. American Psychiatric Association. Diagnostic and statistical manual of mental disorders. 4th ed. Washington, DC: American Psychiatric Association; 2000.

4. Pearlstein T, Howard M, Salisbury A, et al. Postpartum depression. Am J Obstet Gynecol. 2009; 200(4):357364.

5. Cicchetti D, Rogosch FA, Toth SL. The efficacy of toddler-parent psychotherapy for fostering cognitive development in offspring of depressed mothers. J Abnorm Child Psychol. 2000; 28(2):135-148.

6. Ali NS, Mahmud S, Khan A, et al. Impact of postpartum anxiety and depression on child's mental development from two peri-urban communities of Karachi, Pakistan: a quasi-experimental study. BMC Psychiatry. 2013; 13(1): 274.

7. Sutter-Dallay AL, Murray L, Dequae-Merchadou L, et al. A prospective longitudinal study of the impact of early postnatal vs. chronic maternal depressive symptoms on child development. Eur Psychiatry. 2011; 26(8): 484-489.

8. Hay DF, Pawlby S, Sharp D, et al. Intellectual problems shown by 11 year old children whose mothers had postnatal depression. J Child Psychol Psychiatry. 2001; 42(7):871-889.

9. Sinclair D, Murray L. Effects of postnatal depression on children's adjustment to school. Teacher's reports. Br J Psychiatry. 1998; 172(1):5-63.

10. Murray L, Halligan SL, Cooper PJ, Effects of postnatal depression on mother-infant interactions, and child development. In Handbook of infant Development. Oxford, UK: Wiley-Blackwell; 2009.

11. NICHD. Early Child Care Research Network Child care and mother-child interaction in the first three years of life. Dev Psychol. 1999; 35(6):1399-1413.

12. Chronicity of maternal depressive symptoms, maternal sensitivity, and child functioning at 36 months. NICHD Early Child Care Research Network. Dev Psychol. 1999; 35(5):1297-1310.

13. Petterson SM, Albers AB. Effects of poverty and maternal depression on early Child Development. Child Dev. $2001 ; 72(6)$.

14. Ertel KA, Kleinman K, Rossem LV, et al. Maternal perinatal depression is not independently associated with child body mass index in the Generation R Study: methods and missing data matter. J Clin Epidemiol. 2012; 65(12): 1300-1309.

15. Gress-Smith JL, Luecken LJ, Lemery-Chalfant K, et al. Postpartum depression prevalence and impact on infant health, weight, and sleep in low-income and ethnic minority women and infants. Matern Child Health J. 2012; 16(4): 887-893.

16. Milgrom J, Westley DT, Gemmell AW. The mediating role of maternal responsiveness in some longer term effects of postnatal depression on infant development. Infant Behav Dev. 2004; 27(4):443-454. 
17. Stanley C, Murray L, Stein A. The effect of postnatal depression on mother-infant interaction, infant response to the still-face perturbation, and performance on an Instrumental Learning task. Dev Psychopathol. 2004; 16(1):1-18.

18. Zhu Q, Liu XF. Puerperal depression. Chinese Practical Journal of Rural Doctor. 2008; 15(004):9-10.In Chinese.

19. Kalita KN. Developmental profile of infants born to mothers with postpartum depression and anxiety: a comparative study. J Indian Assoc Child Adolesc Ment Health. 2009; 6(1): 3-12.

20. Patel V, DeSouza N, Rodrigues M. Postnatal depression and infant growth and development in low income countries: a cohort study from Goa, India. Arch Dis Child. 2003; 88(1):34-7.

21. Nasreen HE, Kabir ZN, Forsell Y, et al. Impact of maternal depressive symptoms and infant temperament on early infant growth and motor development: results from a population based study in Bangladesh. J Affect Disord. 2013; 146(2): 254-261.

22. Ndokera R and MacArthur $C$. The relationship between maternal depression and adverse infant health outcomes in Zambia: a cross-sectional feasibility study. Child Care Health Dev. 2011; 37(1): 74-81.

23. Bakare MO, Okoye JO and Obindo JT. Introducing depression and developmental screenings into the national programme on immunization (NPI) in southeast Nigeria: an experimental cross-sectional assessment. Gen Hosp Psychiatry. 2014; 36(1): 105-112.

24. Wojcicki J M, Holbrook K, Lustig RH, et al. Chronic Maternal Depression Is Associated with Reduced Weight Gain in Latino Infants from Birth to 2 Years of Age. Plos One. 2011; 6(2):e16737.

25. Grote V, Vik T, von Kries R, et al. Maternal postnatal depression and child growth: a European cohort study. BMC Pediatr. 2010; 10:14.

26. Gaffney KF, Kitsantas P, Brito A, et al. Postpartum depression, infant feeding practices, and infant weight gain at six months of age. J Pediatr Health Care. 2014; 28(1):43-50.

27. Adewuya AO, Ola BO, Aloba OO, et al. Impact of postnatal depression on infants' growth in Nigeria. J Affect Disord. 2008; 108(1-2): 191-193

28. Tomlinson M, Cooper PJ, Stein A, et al. Post-partum depression and infant growth in a South African periurban settlement. Child Care Health Dev. 2006; 32(1): 81-86.

29. Qian YR, Yan XY. Prevalence of postpartum depression in China: a systematic analysis. Chin J Prac Nurs. 2013; 12(29):1-3. In Chinese.

30. Lu JH, Guo Y, Shen SY, et al. Association between inflammatory reaction at late pregnancy and the risk of postpartum depression: A prospective cohort study. Chinese Journal of woman and Child Health Research. 2014; 25(3):391-393. In Chinese.

31. Bai ZL. conometric Analysis of Panel Data. Tian Jin: Nankai University Press. 2008.

32. Baltagi BH. Econometric Analysis of Panel Data. Third edition. New York: Wiley; 2005.

33. Li H. Attach importance to children's growth evaluation and monitoring. Chinese Journal of Child Health Care. 2010; 18(3):180-182. In Chinese.

34. Koning M, Hoekstra $\mathrm{T}$, Jong ED, et al. Identifying developmental trajectories of body mass index in childhood using latent class growth (mixture) modeling: associations with dietary, sedentary and physical activity behaviors: a longitudinal study. BMC Public Health. 2016; 16(1):1128. 
35. Giles LC, Whitrow MJ, Davies MJ, et al. Growth trajectories in early childhood, their relationship with antenatal and postnatal factors, and development of obesity by age 9 years: results from an Australian birth cohort study. Int J Obes (Lond). 2015; 39(7):1049-56.

36. McKeague IW, López-Pintado S, Hallin M. Analyzing growth trajectories. J Dev Orig Health Dis. 2011; 2(6):322-329.

37. Cox JL, Holden JM and Sagovsky R. Detection of postnatal depression. Development of the 10-item Edinburgh Postnatal Depression Scale. Br J Psychiatry.1987; 150: 782-786.

38. Chung EK, McCollum KF, Elo IT, et al. Maternal depressive symptoms and infant health practices among low income women. Pediatrics. 2004; 113(6): e523-e529.

39. Department of maternal and child health and community health, Ministry of health of China. Reference standard for growth of children under 7 years old in China, 2009. http://www.gov.cn/gzdt/200906/02/content_1330290.htm. Accessed 2 Jun, 2009. In Chinese.

40. Zhang L, Huang L, Xiong CH, et al. Application of Linear Mixed Model in Researches of Infant Growth. Chinese Journal of Health Statistics.2015; 32(1):10-13. In Chinese.

41. Sha TT, Yan Y, Gao X, et al. A Comparative Study of Three Statistical Analysis Methods on Baby Growth and Development Follow-up Data. Chinese Journal of Health Statistics.2016; 33(6):951-954. In Chinese.

42. Liu S, Yan Y, Gao X, et al. Risk factors for postpartum depression among Chinese women: path model analysis. BMC Pregnancy Childbirth. 2017; 17(1):133.

43. Cheng G, Sha T, Gao X, et al. Effects of Maternal Prenatal Multi-Micronutrient Supplementation on Growth and Development until 3 Years of Age. Int J Environ Res Public Health. 2019; 16(15):2744.

44. Xie X, Kong BH, Duan T. Obstetrics and Gynecology. 9th Edition. Beijing: People's Health Publishing House; 2018. In Chinese.

45. Schlesselman JJ. Sample size requirements in cohort and case-control studies of disease. Am J Epidemiol. 1974; 99(6):381-384.

46. Little RC, Milliken GA, Stroup WW, et al. SAS System for Mixed Models. Gary North Carolina: SAS Institute Inc; 1996.

47. Department of Nutrition for Health and Development.World Health Organization.The optimal duration of exclusive breastfeeding. Report of an expert

consultation.https://www.who.int/nutrition/publications/optimal_duration_of_exc_bfeeding_report_eng.pdf. Accessed 1 Sept, 2002.

48. Dennis CL, Mcqueen K. The relationship between infant-feeding outcomes and postpartum depression: a qualitative systematic review. Pediatrics. 2009; 123(4):e736 -e751.

49. Alleyne GAO, Hay RW, Picon DI, et al. Protein energy malnutrition. London: Edward Arnold; 1989.

50. Hadley C, Tegegn A, Tessema F, et al. Parental symptoms of common mental disorder and children's social, motor, and language development in sub-Saharan Africa. Annals of Human Biology. 2008; 35(3): $259-275$.

51. Boyd RC, Zayas LH, McKee MD. Mother-Infant interaction, life events and prenatal and postpartum depressive symptoms among urban minority women in primary care. Maternal and Child Health Journal.2006; 10(2):139-148.

52. Mallan KM, Daniels LA, Wilson JL, et al. Association between maternal depressive symptoms in the early postnatal period and responsiveness in feeding at child age 2 years. Matern Child Nutr. 2015; 11(4): 926- 
935

53. Rahman A, lqbal Z, Bunn J, et al. Impact of maternal depression on infant nutritional status and illness: a cohort study. Arch Gen Psychiatry. 2004; 61:946-952.

54. Black MM, Baqui AH, Zaman K, et al. Depressive symptoms among rural Bangladeshi mothers: implication for infant development. J Child Psychol Psychiatry. 2007; 48(8):764-772.

55. Saha KK, Frongillo EA, Alam DS, et al. Appropriate infant feeding practices result in better growth of infants and young children in rural Bangladesh. Am J Clin Nutr. 2008; 87(6):1852-1859.

56. Paulson JF, Dauber S, Leiferman JA. Individual and combined effects of postpartum depression in mothers and fathers on parenting behavior. Pediatrics. 2006; 118(2): 659-668.

57. Bowlby J. Attachment and loss. Attachment 1, Tavistock: London; 1969.

58. O'Hara MW. Postpartum depression: what we know. J Clin Psychol. 2009; 65(12):1258-1269.

59. Taveras EM, Gillman MW, Kleinman K, et al. Racial/ethnic differences in early-life risk factors for childhood obesity. Pediatrics. 2010; 125(4):686-695.

60. Wu JY. The natural outcomes and risk factors of perinatal depression. Hangzhou: Zhejiang University, 2016:1-68. In Chinese.

61. Lara MA, Navarrete L, Nieto L, et al. Prevalence and incidence of perinatal depression and depressive symptoms among Mexican women. J Affect Disord. 2015; 175:18-24.

62. Tchamo ME, Prista A, Leandro CG. Low birth weight, very low birth weight and extremely low birth weight in African children aged between 0 and 5 years old: a systematic review. J Dev Orig Health Dis. 2016; 7(4):408-15

63. Ong KK, Kennedy K, Castañeda-Gutiérrez E, et al. Postnatal growth in preterm infants and later health outcomes: a systematic review. Acta Paediatr. 2015; 104(10):974-86.

64. Huang YL, Liu QJ, Yang YY, et al. Dynamic Changes of Body Mass Index in Infants With Low Birth Weight. Chinese Journal of Child Health Care. 2002; 10(3):187-188. In Chinese.

65. Jennifer W. ACOG releases recommendations on screening for perinatal depression. American Family Physician. 2015; 92(7):648.

66. Premji S, McDonald SW, McNeil DA, et al. Maximizing maternal health and value for money in postpartum depression screening: a cost-effectiveness analysis using the All Our Families cohort and administrative data in Alberta, Canada. J Affect Disord. 2021; 281:839-846.

67. Obstetrics and Gynecology Branch of Chinese Medical Association. Preconception care and prenatal care guidelines (2018). Chinese Journal of Obstetrics and Gynecology. 2018; 53(8):7-13. In Chinese.

68. Li YH. Review of risk factors screening of postpartum depression and its interventions. Chinese General Practice. 2020;23(3): 266-271. In Chinese.

\section{Figures}


Newborns from January to December 2015 to mothers' residents in three streets of Kaifu District $(n=1286)$

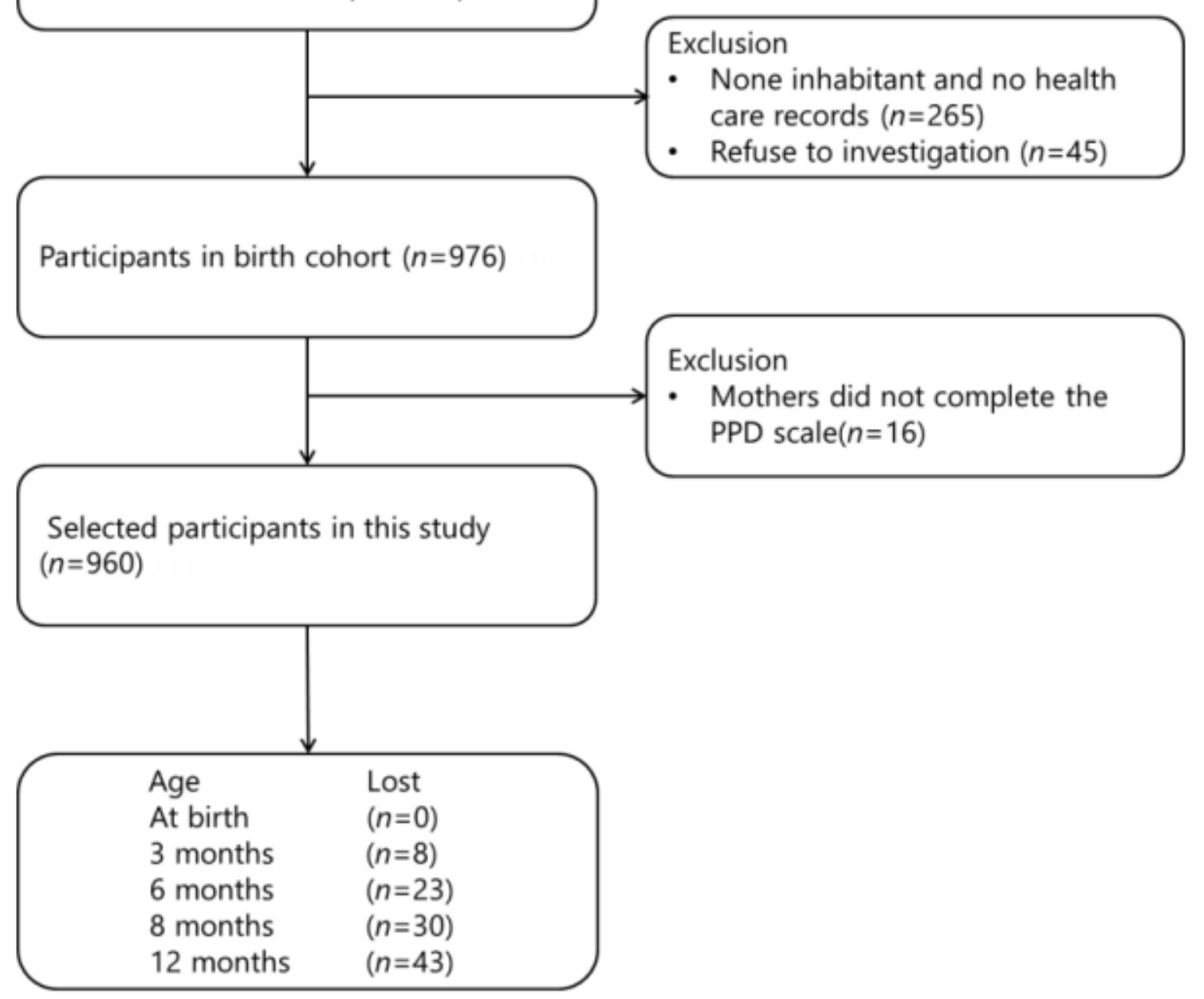

Figure 1

Flow chart of participants in this birth cohort study 